\title{
Effect of WC/Ni-Cr additive on changes in the composition of an atmospheric residue in the course of cracking
}

\author{
Galina S. Pevneva ${ }^{1}$ - Natalya G. Voronetskaya ${ }^{1} \cdot$ Nikita N. Sviridenko $^{1} \cdot$ Anatoly K. Golovko $^{1}$
}

Received: 4 April 2019 / Published online: 19 November 2019

(c) The Author(s) 2019

\begin{abstract}
The paper presents the results of investigation of changes in the composition of hydrocarbons and sulfur-containing compounds of an atmospheric residue in the course of cracking in the presence of a tungsten carbide-nickel-chromium (WC/ $\mathrm{Ni}-\mathrm{Cr}$ ) catalytic additive and without it. The cracking is carried out in an autoclave at $500{ }^{\circ} \mathrm{C}$ for $30 \mathrm{~min}$. The addition of the $\mathrm{WC} / \mathrm{Ni}-\mathrm{Cr}$ additive promotes the deepening of reactions of destruction not only of resins and asphaltenes, but also high molecular weight naphthene-aromatic compounds of the atmospheric residue. It is shown that the content of low molecular weight $\mathrm{C}_{9}-\mathrm{C}_{17} \mathrm{n}$-alkanes and $\mathrm{C}_{9}-\mathrm{C}_{10}$ alkylbenzenes rose sharply in the products of cracking with addition of WC/Ni-Cr in comparison with those produced without the additive. Alkyl- and naphthene-substituted aromatic hydrocarbons of benzene, naphthalene, phenanthrene series, polyarenes, benzo- and dibenzothiophenes are identified.
\end{abstract}

Keywords Atmospheric residue $\cdot$ Cracking $\cdot$ Catalytic additive $\cdot$ Hydrocarbons $\cdot$ Composition

\section{Introduction}

Currently, the main processes for heavy oil residues conversion used at the refineries are coking and hydroprocesses. The increase in super-heavy oils and natural bitumens coming for the refining will necessitate the growth in quantity of heavy oil residues, whose refining will cause a number of problems associated with an increase in the cost of the process due to the use of new catalysts and large amounts of hydrogen, as well as an increase in energy costs (Okunev et al. 2015; Meena and Edward 2017; Holda et al. 2017; Dhir et al. 2016; Kadiev et al. 2017).

Vacuum distillates and residual fractions are characterized by a high content of resins and asphaltenes, heteroatomic compounds and metal-containing components (Yakubov et al. 2016a, b, c). The development of methods for thermal destruction of resins and asphaltenes with simultaneous production of additional amounts of light fractions without using hydrogen will significantly advance the efficiency of

\section{Edited by Xiu-Qiu Peng}

Natalya G. Voronetskaya

voronetskaya@ipc.tsc.ru

1 Institute of Petroleum Chemistry SB RAS, 4 Akademicheskiy Ave, Tomsk, Russia 634055 thermal processing of heavy hydrocarbon feedstock and, as a result, produce petroleum products with a lower content of high molecular weight and heteroatomic compounds and a higher content of distillate fractions (Yakubov et al. 2016a; Morozov et al. 2017; Nassar et al. 2011; Golovko et al. 2015; Sviridenko et al. 2016a, b). Searching of non-conventional methods for conversion of high molecular weight oil compounds requires a study of cracking reactions both in the presence of additives differing in their effects and without them.

This paper is a continuation of researches on the atmospheric residue cracking (Sviridenko et al. 2018). The aim of the work is to study the changes in the individual composition of hydrocarbons and sulfur-containing compounds of atmospheric residue cracking products in the presence of the $\mathrm{WC} / \mathrm{Ni}-\mathrm{Cr}$ additive and without it.

\section{Experimental section}

\subsection{Materials}

The object of the study is the atmospheric residue obtained by distillation of commercial oil at the Novokuibyshevsk refinery. Atmospheric residue is a heavy $\left(11.9^{\circ} \mathrm{API}\right)$ and high-sulfur (3.0 wt\% of sulfur) hydrocarbon feedstock. It is 
Table 1 Physical and chemical characteristics of an atmospheric residue

Indices

\begin{tabular}{lrll}
\hline API gravity & 11.9 & Fractional composition, wt $\%:$ \\
Elemental composition, wt\%: & & Initial boiling point, ${ }^{\circ} \mathrm{C}$ & 343.0 \\
Carbon & 82.2 & $343-360{ }^{\circ} \mathrm{C}$ & 1.4 \\
Hydrogen & 10.7 & $360-500^{\circ} \mathrm{C}$ & 77.9 \\
Sulfur & 3.0 & Residue $>500{ }^{\circ} \mathrm{C}$ & 20.7 \\
Nitrogen & 0.2 & SARA, $w t \%:$ & $35.1+25.6$ \\
Oxygen & 3.9 & Saturates + aromatics & 33.6 \\
H/C & 1.56 & Resins & 5.7 \\
& & Asphaltenes & \\
\hline
\end{tabular}

characterized by high thermal stability, since it has already been heat-treated. According to the data of its fractional composition, the content of fractions boiling within the temperature range $343-500{ }^{\circ} \mathrm{C}$ is $77.9 \mathrm{wt} \%$, while that of the residue boiling above $500{ }^{\circ} \mathrm{C}$ is $20.7 \mathrm{wt} \%$ (Table 1). The amount of high molecular weight components such as resins and asphaltenes reaches $39.3 \%$. The atomic $\mathrm{H} / \mathrm{C}$ ratio (1.56) suggests an aromaticity of the components contained in the atmospheric residue.

\subsection{Catalytic additive}

To increase the depth of destruction of the resins and asphaltenes, a catalytic $\mathrm{WC} / \mathrm{Ni}-\mathrm{Cr}$ additive in the form of micron-sized powder was used. It had a small specific surface $\left(\mathrm{S}=0.4014 \mathrm{~m}^{2} / \mathrm{g}\right)$ and contained $\mathrm{W}(24.1 \%), \mathrm{C}(3.1 \%)$, $\mathrm{Ni}(51.3 \%), \mathrm{Cr}(15.9), \mathrm{Fe}(3.7 \%)$ and $\mathrm{O}(1.9 \%)$. The catalytic additive was prepared in several stages as follows:

- Tungsten carbide resulted from the carbidization of $\mathrm{WO}_{3}$ at $850{ }^{\circ} \mathrm{C}$ using $\mathrm{CH}_{4} / \mathrm{H}_{2}$ gas mixtures as a carburizing agent;

- Nichrome powder was obtained by the method of electric explosion of wire of Nichrome 80;

- A mixture of tungsten carbide and nichrome powder was mechanically treated in an AGO-2 M planetary ball milling machine. The duration of the mechanical treatment was $30 \mathrm{~min}$, and the rotation speed of grinding was $1180 \mathrm{rpm}$. The average size of resulted particles was $22-35 \mu \mathrm{m}$.

There is a lack of information about the use of the WC/ $\mathrm{Ni}-\mathrm{Cr}$ catalytic additive in thermal processing of hydrocarbon feedstock in the literature, although each of the components of the additive was separately studied in various catalytic processes (Morozov et al. 2017; Rodella et al. 2015; Semin et al. 2012; MacAdams et al. 2005; Furimsky 2003; Ledoux et al. 1992). Earlier, we reported that the addition of WC/Ni-Cr contributes to the cracking of large hydrocarbon

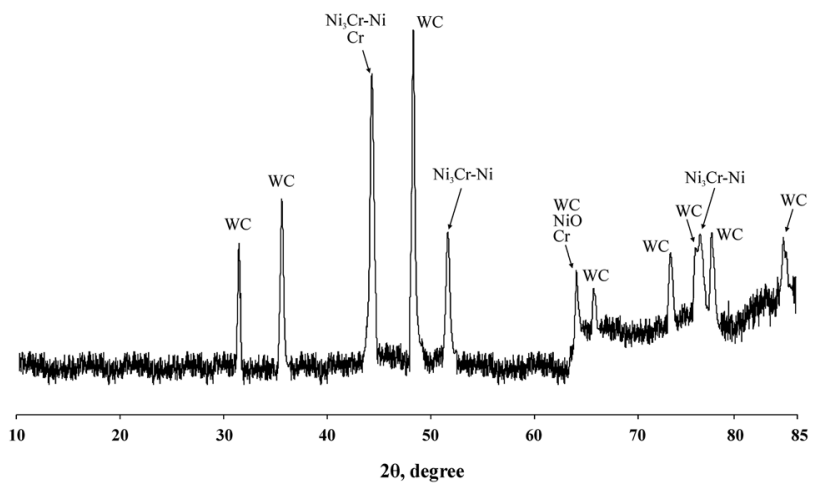

Fig. 1 XRD pattern of the $\mathrm{WC} / \mathrm{Ni}-\mathrm{Cr}$ additive

molecules and the redistribution of hydrogen (Sviridenko et al. 2018).

The structure of the catalytic additive was investigated via X-ray diffraction analysis (D8 Bruker XRD-powder diffractometer), electron microscopy and microprobe analysis (Hitachi TM-1000 scanning electron microscope with energy-dispersive X-ray spectrometer). Figure 1 shows the $\mathrm{X}$-ray diffraction pattern of a catalytic additive, which has the following phase composition: WC in hexagonal modification $\left(2 \theta=31.5^{\circ} ; 35.6^{\circ} ; 48.3^{\circ} ; 64.1^{\circ} ; 65.8^{\circ} ; 73.2^{\circ} ; 75.8^{\circ}\right.$; $77.1^{\circ}$ and $\left.84.3^{\circ}\right), \mathrm{Ni}_{3} \mathrm{Cr}$ in a cubic modification $\left(2 \theta=44.3^{\circ}\right.$; $51.7^{\circ}$ and $\left.76.1^{\circ}\right)$, $\mathrm{Ni}$ in a cubic modification $\left(2 \theta=44.3^{\circ}\right.$; $51.7^{\circ}$ and $\left.76.1^{\circ}\right), \mathrm{Cr}$ in a cubic modification $\left(2 \theta=44.3^{\circ}\right.$ and $\left.64.1^{\circ}\right), \mathrm{NiO}$ in a hexagonal modification $\left(2 \theta=64.1^{\circ}\right)$ and $\mathrm{NiO}_{2}$ in a cubic modification $\left(2 \theta=84.3^{\circ}\right)$.

Figure 2 gives micrographs of tungsten carbide and nichrome and their energy dispersion spectra. It is evident from these spectra that the $\mathrm{WC} / \mathrm{Ni}-\mathrm{Cr}$ powder consists of tungsten carbide particles with small amounts of nickel, chromium, iron and oxygen on its surface (Fig. 2a), while the particles of tungsten, carbon, iron and oxygen are present on the surface of nichrome (Fig. 2b). 


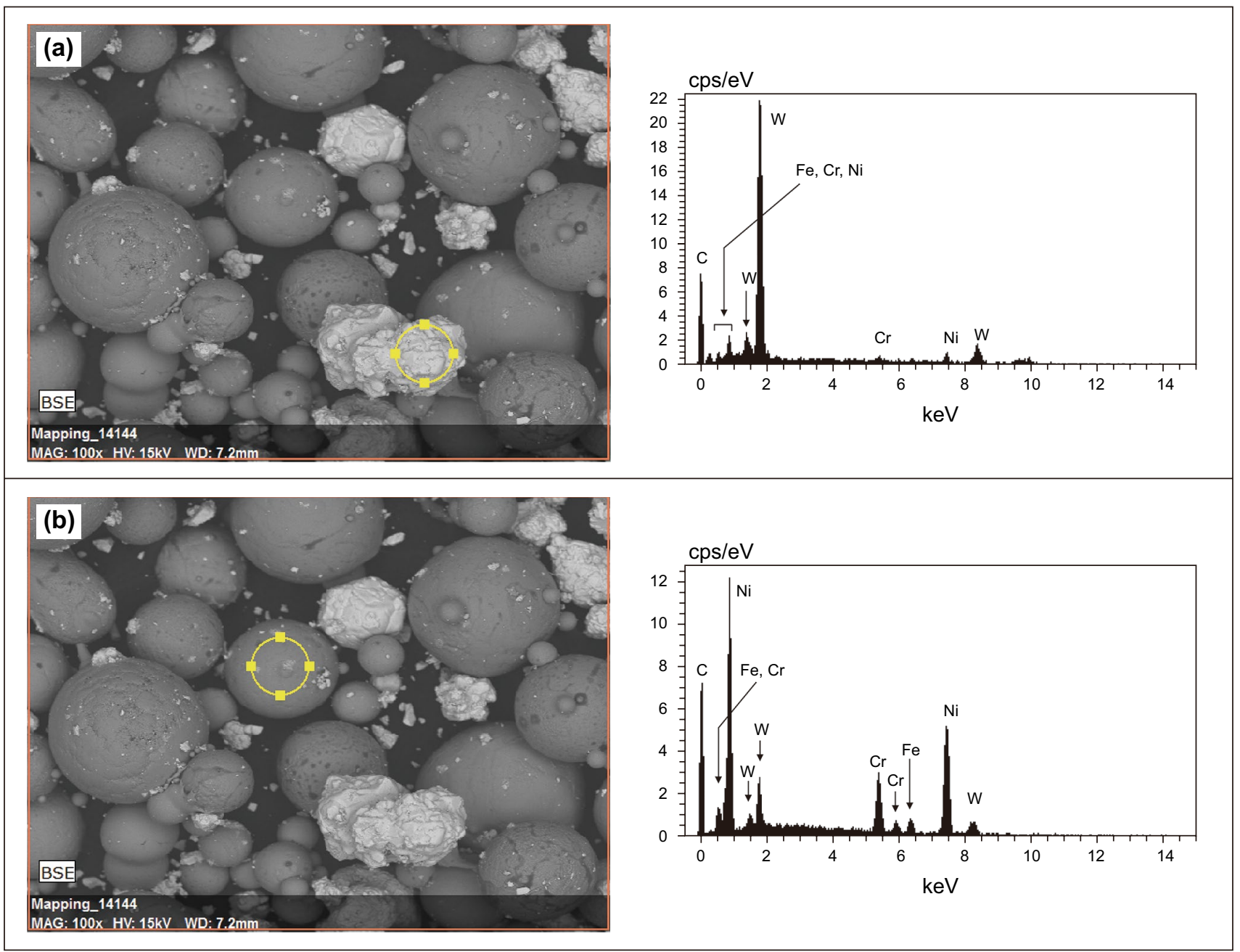

Fig. 2 BSE image of the additive and the energy-dispersive spectrum of particles of tungsten carbide (a) and nichrome (b)

\subsection{Cracking conditions}

The cracking of atmospheric residue was carried out autoclave at $500{ }^{\circ} \mathrm{C}$ for $30 \mathrm{~min}$ in a $12 \mathrm{~cm}^{3}$ close batch reactor. It was shown (Sviridenko et al. 2018) that for a given cracking duration the maximum yield in light fractions boiling up to $360{ }^{\circ} \mathrm{C}$ was reached. The mass of atmospheric residue charged into the reactor was $7 \mathrm{~g}$. The amount of additive was $0.1 \mathrm{wt} \%$ per the mass of atmospheric residue (Sviridenko et al. 2018). Cracking of feedstock with and without the additive was carried out under identical conditions.

The mass balance of the cracking process was evaluated by the yield in gaseous, liquid and solid products. The gaseous products' yield was determined based on the reactor weight change after gaseous products were removed. The liquid products were eluted from the reactor, followed by reactor wash with chloroform. The liquid products of thermal cracking and chloroform solution were further combined and filtered using paper filter in order to remove solids. The solvent then was evaporated via rotary evaporator, and the liquid products were dried under vacuum to their constant weight.

The difference between masses of products that were not flashed out from the reactor and the entered additive was determined as the yield of solids. By 'solids,' we meant coke-like condensation products, insoluble in polar organic solvents. In this work, they have not been studied.

\subsection{Research methods}

\subsubsection{SARA analysis}

To isolate asphaltenes, the sample was treated with a 40-fold excess of n-hexane and the solution was held for $24 \mathrm{~h}$. The precipitate was filtered off, placed into a paper cartridge and washed with hexane from hydrocarbons and resins in the Soxhlet apparatus. Then, asphaltenes were washed out from the cartridge with chloroform, and the 
Table 2 Composition of the initial atmospheric residue and products of cracking

\begin{tabular}{|c|c|c|c|c|c|c|}
\hline \multirow[t]{2}{*}{ Sample } & \multicolumn{6}{|l|}{ Content, wt $\%$} \\
\hline & $\begin{array}{l}\text { Fractions boiling up } \\
\text { to } 360^{\circ} \mathrm{C}\end{array}$ & Saturates + aromatics & Resins & Asphaltenes & Coke & Gas \\
\hline Initial atmospheric residue & 1.4 & $35.1+25.6$ & 33.6 & 5.7 & & \\
\hline Cracking without the additive & 27.4 & $23.8+30.9$ & 16.1 & 10.5 & 10.4 & 8.3 \\
\hline $\begin{array}{l}\text { Cracking in the presence of } 0.1 \mathrm{wt} \% \\
\text { of additive }\end{array}$ & 67.8 & $43.0+33.8$ & 8.1 & 2.2 & 6.2 & 6.7 \\
\hline
\end{tabular}

solvent was evaporated. The yield in asphaltenes was determined after drying of the sample to a constant weight. Resins were isolated from hydrocarbons by the method of hot extraction in a Soxhlet apparatus (STO).

Maltenes that resulted from the deasphaltization were placed on the layer of activated large pore silica in 1:20 ratio. The mixture of silica gel and the adsorbed maltenes was loaded into the Soxhlet extractor. First, saturates and aromatics were extracted with $n$-hexane and then resins were successively extracted with a mixture of ethanol and benzene $(1: 1)$ at the boiling temperatures of the abovenoted solvents. After the removal of solvents from the hexane and alcohol-benzene eluates and bringing to a constant weight, the content of hydrocarbons (saturated + aromatic) and resins was determined, respectively.

\subsubsection{Gas chromatography-mass spectrometry analysis (GC-MS)}

Gas chromatography-mass spectrometry analysis (GC-MS analysis) of the composition of saturates and aromatics was performed using a quadrupole system Shimadzu GCMS-QP5050A. To separate the components, a CR5-MS capillary column (30 m length, $0.25 \mathrm{~mm}$ ID and $0.25 \mu \mathrm{m}$ film thickness of 5\% phenyl- 95\% dimethylpolysiloxane) was used. The carrier gas was helium. The split ratio was $1: 12$. The analysis was carried out in the scan acquisition mode (full scanning of ions in the mass range from 50 to $800 \mathrm{amu})$. The temperature was programmed from 80 to $290{ }^{\circ} \mathrm{C}$ with heating rate of $2{ }^{\circ} \mathrm{C} / \mathrm{min}$. The final temperature was held constant for $25 \mathrm{~min}$. The ionization energy was $70 \mathrm{eV}$, and the temperatures of injector and interface were $290{ }^{\circ} \mathrm{C}$. Data were acquired and processed by the GCMSsolution software. The compounds were identified using NIST and Willey mass spectra libraries for the reference.

\section{Results and discussion}

\subsection{Cracking of an atmospheric residue}

Table 2 presents data on the mass balance of the liquid products of atmospheric residue cracking in the presence of the $\mathrm{WC} / \mathrm{Ni}-\mathrm{Cr}$ additive and without it. A significant content of asphaltenes $(10.5 \%)$ and coke $(10.4 \%)$ in products of cracking without the use of the additive indicates that reactions of recombination of formed free radicals with condensed structure on the route hydrocarbons $=>$ resins $=>$ asphaltenes $=>$ coke prevail over destruction reactions (asphaltenes $=>$ resins $=>$ hydrocarbons $=>$ gas) (Dmitriev and Golovko 2010; Wang et al. 2009). The content of resins in liquid products of cracking decreases almost 2 times (Table 2). The decrease in the amount of (saturates + aromatics) by $6.0 \%$ compared with the initial atmospheric residue was partly due to reactions of gas formation (8.3 wt $\%$ ) and partly due to the participation of polycyclic hydrocarbons in the formation of asphaltenes. Despite the decrease in the content of (saturates + aromatics), their qualitative composition was improved. In this case, the yield in light fractions boiling up to $360{ }^{\circ} \mathrm{C}$ increases to $27.4 \mathrm{wt} \%$, probably due to the destruction of resins and/or high molecular weight hydrocarbons.

Maximal destruction of atmospheric residue components is achieved by cracking with the addition of $\mathrm{WC} / \mathrm{Ni}-\mathrm{Cr}$. The yields in by-products gas and coke are lower by 1.6 and 4.2 wt.\%, respectively, than in the case of cracking without the additive. The content of asphaltenes in this case is minimal and amounts to $2.2 \mathrm{wt} \%$. The amount of resins is reduced by $25.5 \%$ compared with the initial atmospheric residue and by $8.0 \mathrm{wt} \%$ compared to cracking without the additive. In liquid products of cracking with the addition of $\mathrm{WC} / \mathrm{Ni}-\mathrm{Cr}$, the content of hydrocarbons (saturates + aromatics) increases by $18.1 \%$ compared to the initial atmospheric residue and by $22.1 \mathrm{wt} \%$ compared to cracking without the additive. It is shown that the addition of $\mathrm{WC} / \mathrm{Ni}-\mathrm{Cr}$ contributes to an increase in the yield of distillate fractions boiling up to $360{ }^{\circ} \mathrm{C}$ by $66.4 \%$, compared with the initial atmospheric residue. 
Thus, the addition of $\mathrm{WC} / \mathrm{Ni}-\mathrm{Cr}$ retards the reactions of recombination of free radicals with condensed structure of resins as evidenced by a significant decrease in the content of asphaltenes and coke compared with the products of cracking without the $\mathrm{WC} / \mathrm{Ni}-\mathrm{Cr}$ additive. At the same time, a deep destruction of resins is observed. It results in the formation of low molecular weight hydrocarbon components, which are part of light fractions (León et al. 2017).

\subsection{Hydrocarbon composition}

Detailed information on the composition of various types of saturated and aromatic compounds in the initial atmospheric residue and products of cracking was obtained from the analysis of the mass fragmentation patterns of the characteristic ions. The products of atmospheric residue cracking in the presence of $\mathrm{WC} / \mathrm{Ni}-\mathrm{Cr}$ and without it differ significantly from the initial atmospheric residue in the compositions of saturated and aromatic compounds. Products of cracking are characterized by a wider range of identified hydrocarbons and organic sulfur compounds. The relative contents of identified compounds of all types were determined as the ratios of the peak areas on the characteristic mass fragmentograms to the sum of areas under all the peaks recorded during GCMS analysis of sample.

A high naphthenic hump was observed in the region of elution of high molecular weight $n$-alkanes (above $\mathrm{C}_{25}$ ) on the total ion current (TIC) chromatogram for the initial atmospheric residue. This suggests the presence of a complex unseparated mixture of high molecular weight and high boiling naphthenic and aromatic compounds (Fig. 3a) (Antipenko et al. 2015).

Apart from the naphthenic hump, the peaks occurred, which were identified as $\mathrm{C}_{26}-\mathrm{C}_{40} \mathrm{n}$-alkanes. It is noteworthy that the areas of naphthenic humps on the TIC chromatograms of both products of cracking were significantly decreased (Fig. 3b, c). This is especially noticeable for products of cracking with $\mathrm{WC} / \mathrm{Ni}-\mathrm{Cr}$.

In the initial atmospheric residue, only n-alkanes $(\mathrm{m} / \mathrm{z}$ 57) and hopanes (m/z 191) were identified. The content of n-alkanes was $10.3 \%$ rel., and that of hopanes was $1.2 \%$ rel. Hopanes were represented by $\mathrm{C}_{29}-\mathrm{C}_{35}$ compounds with a predominance of $\mathrm{C}_{30}$ hopane.

The homologous series of $n$-alkanes were composed of $\mathrm{C}_{18}-\mathrm{C}_{40}$ compounds. The maximum in the molecular mass distribution (MMD) accounted for $\mathrm{C}_{35}-\mathrm{C}_{36}$ high molecular weight homologues (Fig. 4). The total content of $\mathrm{C}_{18}-\mathrm{C}_{28}$ n-alkanes was $17.2 \%$ rel., and that of $\mathrm{C}_{29}-\mathrm{C}_{40}$ was $82.8 \%$ rel.

There are no clearly defined peaks on the mass fragmentograms for the characteristic ions of other types of naphthenic and aromatic hydrocarbons (AHCs), which did not permit to identify them.
The MMD of $n$-alkanes of both products of cracking differs significantly in their qualitative and quantitative characteristics from each other and from the MMD for the initial atmospheric residue (Figs. 3, 4). As shown above, low molecular weight $\mathrm{C}_{9}-\mathrm{C}_{17} \mathrm{n}$-alkanes are absent in the initial atmospheric residue.

The homologous series of $n$-alkanes of the products of cracking without the additive were formed by compounds with the number of carbon atoms in the molecule ranged from 12 to 40. The maximum on the MMD curve is wide and covers the region from $\mathrm{C}_{18}$ to $\mathrm{C}_{26} \mathrm{n}$-alkane. The content of $\mathrm{C}_{12}-\mathrm{C}_{17} \mathrm{n}$-alkanes in these products of cracking is $17.8 \%$ rel. The percentage of $\mathrm{C}_{18}-\mathrm{C}_{28} \mathrm{n}$-alkanes increases to $55.0 \%$ rel., while that of high molecular weight $\mathrm{C}_{29}-\mathrm{C}_{40}$ homologues decreases to $27.2 \%$ compared to the initial atmospheric residue. The formation of low molecular weight $\mathrm{C}_{12}-\mathrm{C}_{17} \mathrm{n}$-alkanes and the increase in the content of medium molecular weight $\mathrm{C}_{18}-\mathrm{C}_{28} \mathrm{n}$-alkanes in products of cracking occurs due to the destruction of resins and/or high molecular weight compounds that are an integral part of the naphthenic hump.

The n-alkanes of products of cracking with the addition of WC/Ni-Cr exhibit a fundamentally different MMD pattern (Figs. 3,4). The presence of a catalytic additive contributes to the deepening of destruction reactions during cracking, resulting in a formation of a significant amount of low molecular weight $\mathrm{C}_{9}-\mathrm{C}_{17} \mathrm{n}$-alkanes. Their percentage reaches $53.9 \%$ rel., and, as a result, the content of higher molecular weight homologues of $\mathrm{C}_{18}-\mathrm{C}_{28}$ and $\mathrm{C}_{29}-\mathrm{C}_{40}$ n-alkanes decreases to 36.3 and $9.8 \%$ rel., respectively. This proves the fact that the $\mathrm{WC} / \mathrm{Ni}-\mathrm{Cr}$ additive has cracking properties; hence, its presence determines the tendency of thermal transformations of high molecular weight components of an atmospheric residue.

In addition to n-alkanes, in the products of cracking with and without the $\mathrm{WC} / \mathrm{Ni}-\mathrm{Cr}$ additive, alkyl cyclohexanes $(\mathrm{m} / \mathrm{z}$ 83) have been identified, whose homologous series consisted of $\mathrm{C}_{15}-\mathrm{C}_{23}$ and $\mathrm{C}_{11}-\mathrm{C}_{23}$ compounds, respectively. Also, as in the composition of $n$-alkanes, the percentage of low molecular weight alkyl cyclohexanes in products of cracking with the addition of $\mathrm{WC} / \mathrm{Ni}-\mathrm{Cr}$ was higher than in those without this additive. Alkyl cyclohexanes have not been identified in the initial atmospheric residue. It should be noted that the presence of hopanes $(\mathrm{m} / \mathrm{z}$ 191) was not established for both products of cracking.

Before proceeding to the analysis of the composition of cyclic aromatic hydrocarbons, it should be emphasized that the content of these compounds in the initial atmospheric residue was not determined. As an example, in Fig. 5a the mass fragmentogram of $n$-alkyltoluenes $(\mathrm{m} / \mathrm{z} 105)$ of the initial atmospheric residue is shown. The total content of the identified aromatic hydrocarbons in the products of cracking was $4.2 \%$ rel. 
(a)

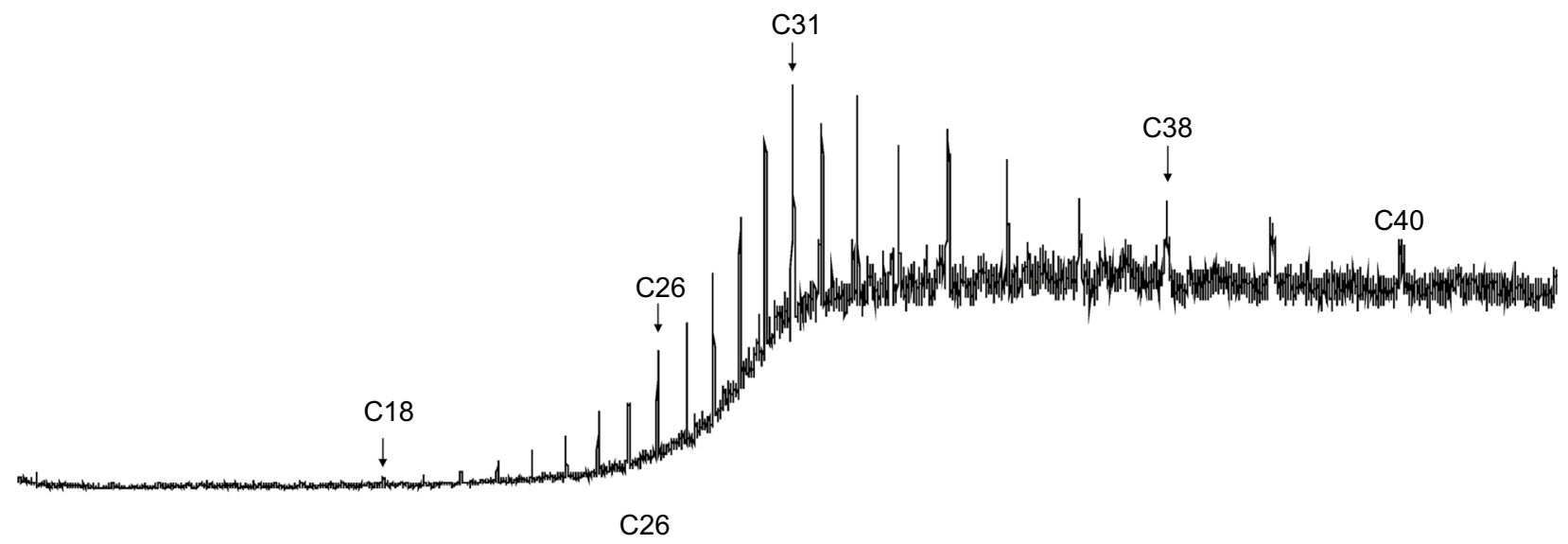

(b)

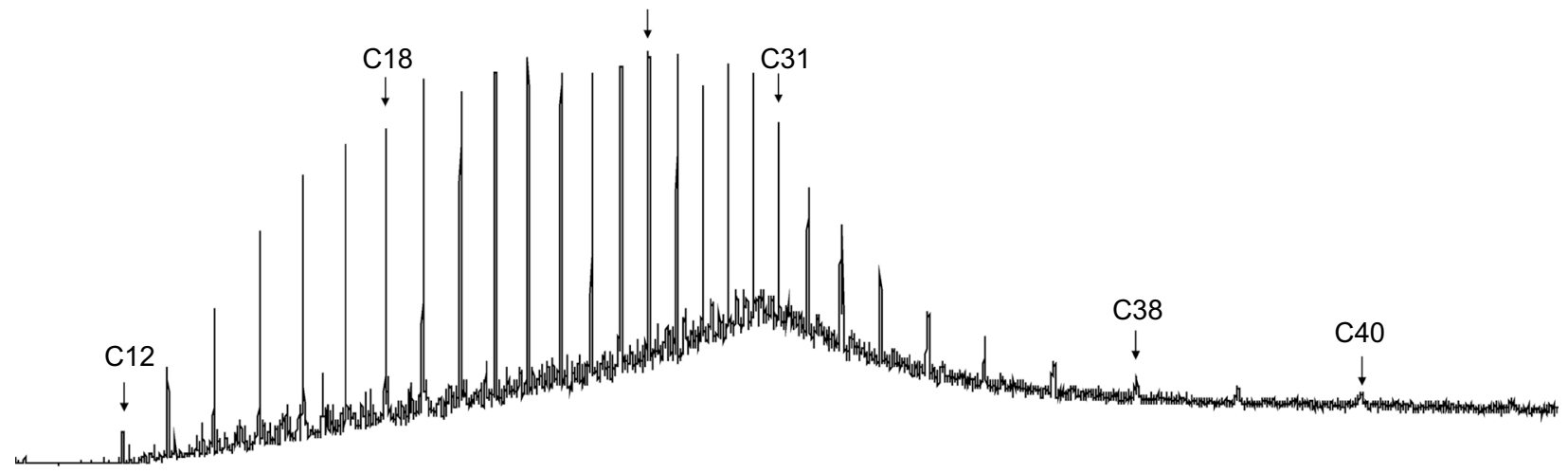

(c)

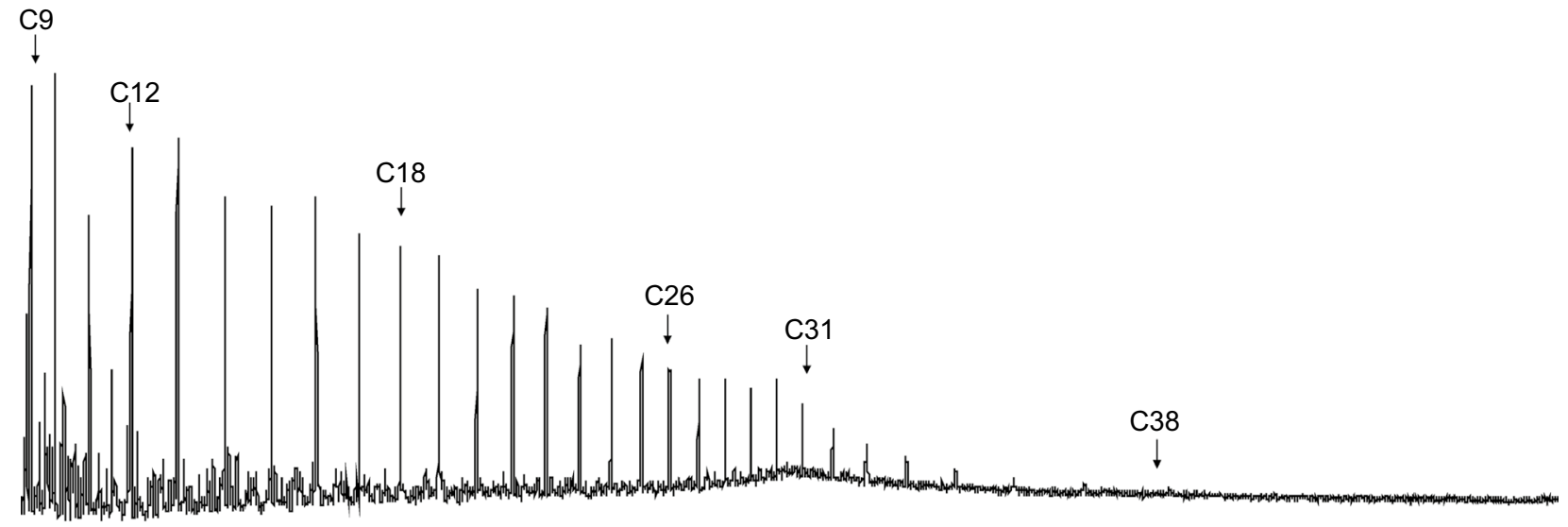

Fig. 3 TIC chromatograms of initial atmospheric residue (a), products of thermal cracking without the additive (b) and products of cracking with WC/Ni-Cr (c)

Monocyclic AHCs in products of cracking without the additive were represented by two homologous series-nalkylbenzenes (m/z 91) and n-alkyltoluenes (m/z 105) —with a total number of carbon atoms in the molecule from 12 to 32 (Fig. 5b). The presence of peaks of tri- and tetrasubstituted alkyl benzenes was observed on the mass fragmentograms of the corresponding m/z 119 and 133 ions, but they were difficult to reliably identify due to their low content. Figure 5a shows the distribution of benzene homologues by their concentration in the initial atmospheric residue and products of cracking.

Changes in the MMD of alkyl benzenes in products of cracking with the $\mathrm{WC} / \mathrm{Ni}-\mathrm{Cr}$ additive suggest a deeper process of destruction. This is indicated by the fact that the first members of the homologous series of alkyl-substituted benzenes and toluenes in these products are $\mathrm{C}_{8}$ dimethylbenzenes (xylenes) (Fig. 5c). However, in products of cracking without the $\mathrm{WC} / \mathrm{Ni}-\mathrm{Cr}$ additive their homologous series begin with $\mathrm{C}_{12}$ homologues. The n-alkylbenzenes 


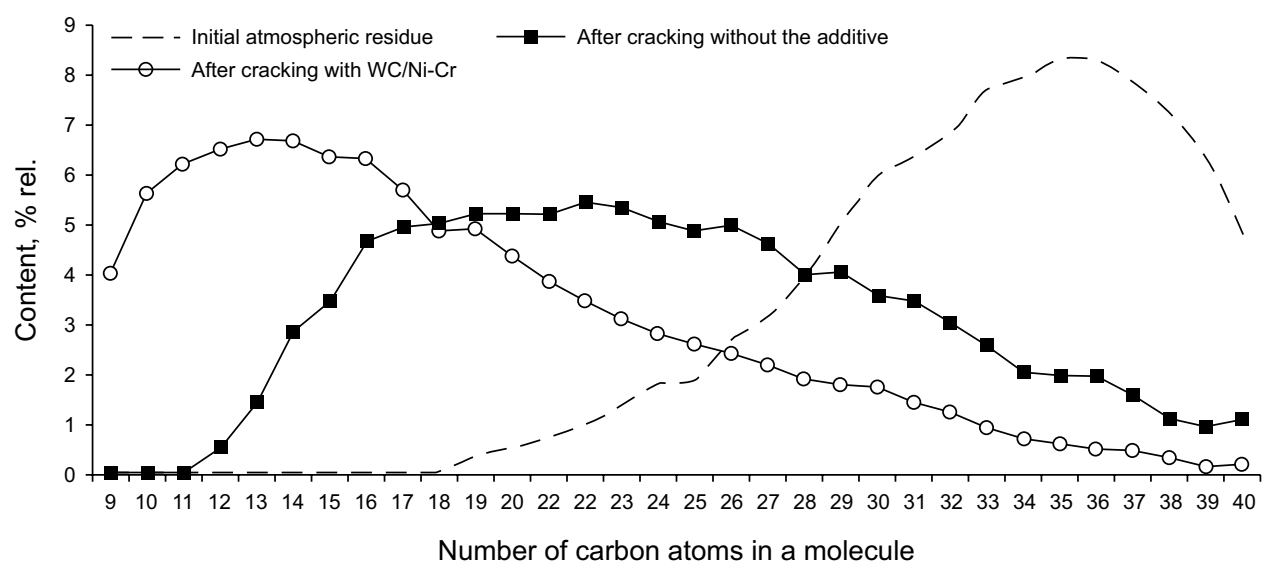

Fig. 4 Molecular mass distribution of $n$-alkanes of the initial atmospheric residue and products of cracking

(a)

(b)

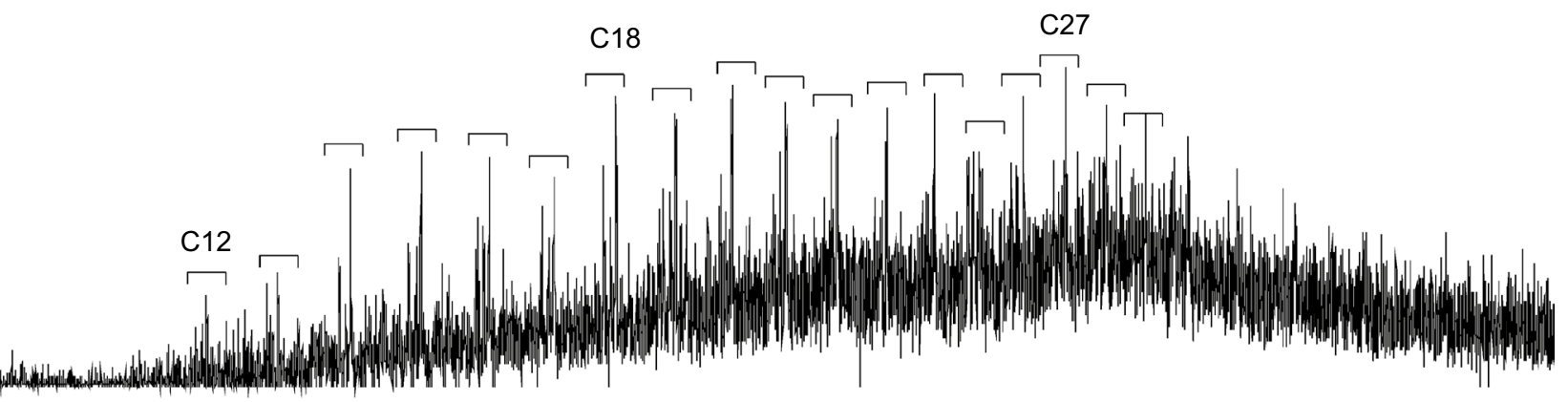

(c)

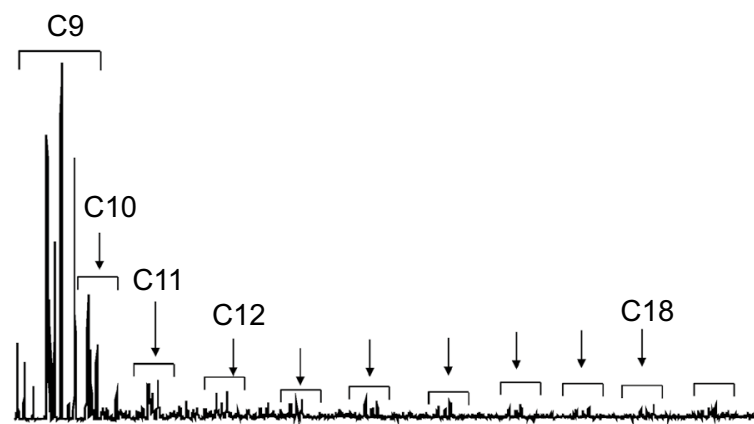

Fig. 5 Mass fragmentograms of $n$-alkyltoluenes $(\mathrm{m} / \mathrm{z}$ 105) of the initial atmospheric residue (a), products of thermal cracking without the additive (b), and products of cracking with $\mathrm{WC} / \mathrm{Ni}-\mathrm{Cr}(\mathbf{c})$ 

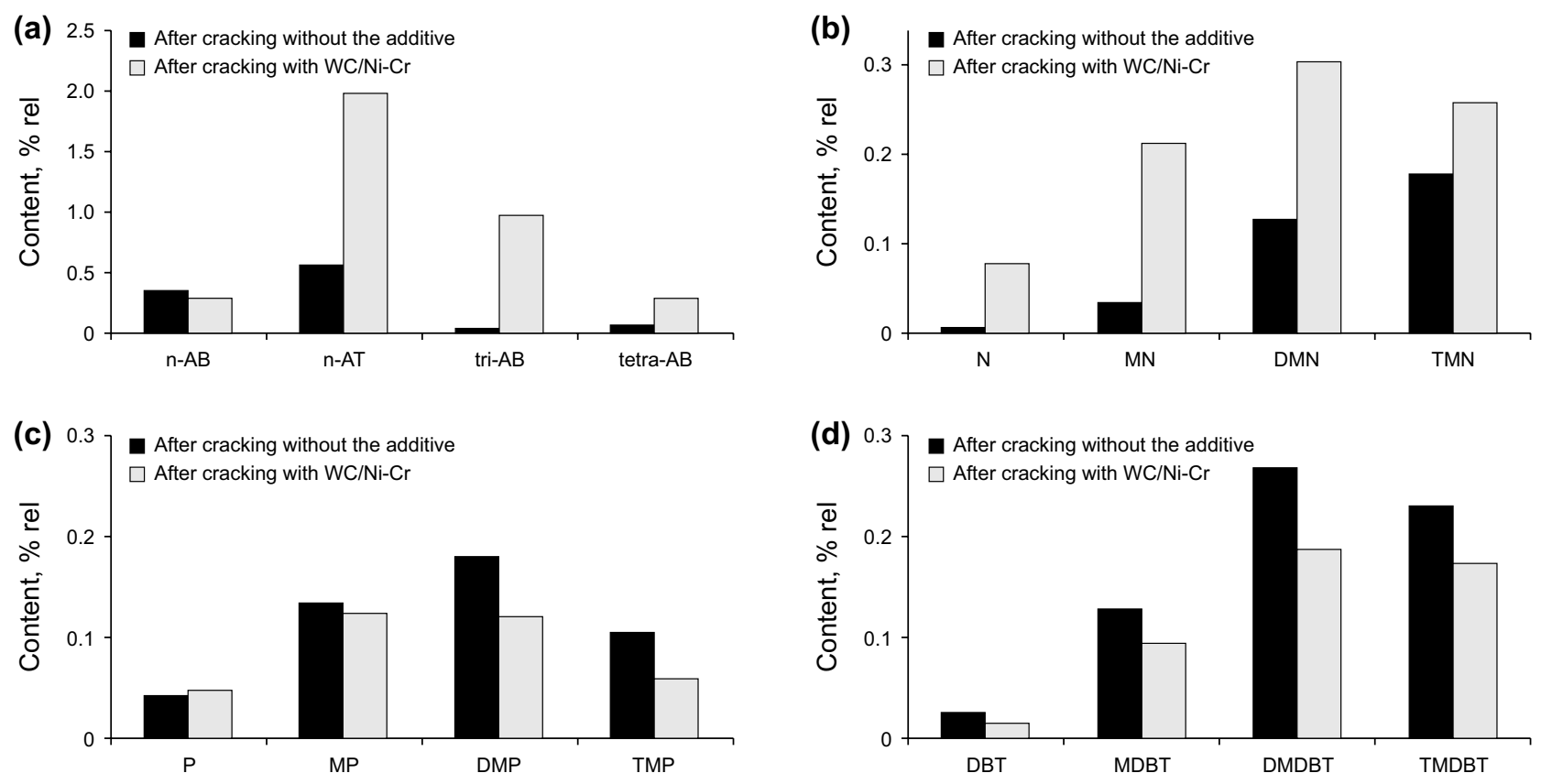

\footnotetext{
* $\mathrm{n}$-AB - n-alkylbenzenes, $\mathrm{n}$-AT - n-alkyltoluenes, tri-AB - trisubstituted alkylbenzenes, tetra-AB - tetrasubstututed alkylbenzenes; $\mathrm{N}$ - naphthalene, $\mathrm{MN}$ - metylnaphthalenes, DMN - dimetylnaphthalenes, TMN - trimetylnaphthalenes; $\mathrm{P}$ - phenanthrene, $\mathrm{MP}$ - metylphenanthrenes, DMP - dimetylphenanthrenes, TMN - trimetylphenanthrenes;

DBT - dibenzothiophene, MDBT - methyllibenzothiophenes, DMDBT - dimetyldibenzothiophenes, TMDBT — trimetyldlibenzothiophenes.
}

Fig. 6 Group composition of alkyl-substituted benzenes (a), naphthalenes (b), phenanthrenes (c) and dibenzothiophenes (d)

were represented by compounds with 8-26 carbon atoms in the molecule, while n-alkyltoluenes by those with $8-20$ carbon atoms. Concentrations of $\mathrm{C}_{11+} \mathrm{n}$-alkyltoluenes were extremely low compared to the content of their $\mathrm{C}_{9}$ and $\mathrm{C}_{10}$ homologues. Among tri- (m/z 119) and tetrasubstituted (m/z 133) alkyl benzenes, the prevalence of $\mathrm{C}_{9}$ and $\mathrm{C}_{10}$ homologues was observed. The presence of homologues with long alkyl substituents on the mass fragmentograms for $\mathrm{m} / \mathrm{z} 119$ and 133 has not been established, since the height of their peaks did not exceed the background level.

Besides alkyl benzenes, naphthenic-substituted benzenes - indane, tetralin, and its $\mathrm{C}_{1}-\mathrm{C}_{2}$ homologues-were identified in both products of cracking.

Bicyclic AHCs were represented by unsubstituted naphthalene $(\mathrm{m} / \mathrm{z} 128)$ and its methyl-substituted $\mathrm{C}_{1}-\mathrm{C}_{4}$ homologues $(\mathrm{m} / \mathrm{z} 142,156,170,184)$, as well as by diphenyls $(\mathrm{m} / \mathrm{z} 154,168)$. The distributions of naphthalene homologues by concentrations in both products of cracking were similar. Their concentration series were as follows: trimethyl- $>$ dimethyl- $>$ monomethyl- $>$ unsubstituted naphthalene $>$ tetramethylnaphthalenes (Fig. 6b). The total content of naphthalenes and diphenyls in products of cracking with $\mathrm{WC} / \mathrm{Ni}-\mathrm{Cr}$ was higher by $\sim 2.5$ times than that in products of cracking without the additive. Among naphthene-substituted biarenes, the presence of fluorene $(\mathrm{m} / \mathrm{z} 165)$ and 9,10-dihydroanthracene $(\mathrm{m} / \mathrm{z}$ 170) has been established.

Among tricyclic AHCs in both products of cracking, unsubstituted phenanthrene $(\mathrm{m} / \mathrm{z} 178)$ and its homologues to $\mathrm{C}_{4}(\mathrm{~m} / \mathrm{z} 192,206,220,234)$, as well as anthracene, have been identified. The total content of tricyclic AHCs and the content of bicyclic AHCs in products of cracking with the addition of $\mathrm{WC} / \mathrm{Ni}-\mathrm{Cr}$ were lower than that without the additive (Fig. 6c). Tetracyclic AHCs were represented by fluoranthene, pyrene $(\mathrm{m} / \mathrm{z} 202,216)$, triphenylene, chrysene $(\mathrm{m} / \mathrm{z} 228)$ and benzopyrene $(\mathrm{m} / \mathrm{z} 253)$.

Benzothiophenes with the total number of carbon atoms from 2 to 6 in alkyl substituents of the aromatic nucleus $(\mathrm{m} / \mathrm{z} 148,162)$, naphthobenzothiophenes $(\mathrm{m} / \mathrm{z}$ 234), dibenzothiophene (DBT) and its homologues from mono- to tetrasubstituted $(\mathrm{m} / \mathrm{z} 184,198,212,226)$ were identified in both products of cracking (Fig. 6d). 


\section{Conclusions}

The composition of products of cracking in the presence of the WC/Ni-Cr catalytic additive and without it has been analyzed, and the following has been established:

- The addition of WC/Ni-Cr retards the reactions of condensation of free radicals with condensed structure of resins formed in the course of cracking and the destruction reactions resulted in the formation of gaseous products of cracking. In this case, the deep destruction of resins with the abstraction of aliphatic fragments occurs, resulting in the formation of low molecular weight hydrocarbon components of light fractions. The yield in light fractions boiling up to $360{ }^{\circ} \mathrm{C}$ increases by $66.4 \%$ compared with the initial atmospheric residue and by $40.4 \%$ compared with the cracking without the additive.

- The addition of $\mathrm{WC} / \mathrm{Ni}-\mathrm{Cr}$ contributes to the deepening of destruction reactions not only of resins and asphaltenes but also of high molecular weight naphtheno-aromatic compounds of the atmospheric residue. It has been shown that in liquid products of cracking with $\mathrm{WC} / \mathrm{Ni}-\mathrm{Cr}$ additive the amount of low molecular weight $\mathrm{C}_{9}-\mathrm{C}_{17} \mathrm{n}$-alkanes and $\mathrm{C}_{9}-\mathrm{C}_{10}$ alkyl benzenes increases sharply compared to cracking without the additive. Alkyl- and naphthene-substituted aromatic hydrocarbons of benzene, naphthalene and phenanthrene series have also been identified, as well as polyarenes and benzo-, and dibenzothiophenes.

Open Access This article is distributed under the terms of the Creative Commons Attribution 4.0 International License (http://creativeco mmons.org/licenses/by/4.0/), which permits unrestricted use, distribution, and reproduction in any medium, provided you give appropriate credit to the original author(s) and the source, provide a link to the Creative Commons license, and indicate if changes were made.

\section{References}

Antipenko VR, Bakanova OS, Melenevsky VN, Elchaninova EA. Composition of 'bound' compounds in oil components of biodegraded oils based on the results of their 'on-line' flash pyrolysis. Bull Tomsk Polytech Univ. 2015;326(6):46-55.

Dhir S, Mahapatra N, Kurian V, Alipour M, Gupta R. Single particle asphaltene pyrolysis in a drop-tube furnace. Energy Fuels. 2016;30(7):6132-42. https://doi.org/10.1021/acs.energyfuel s.6b01195.

Dmitriev DE, Golovko AK. Transformations of resins and asphaltenes during the thermal treatment of heavy oils. Pet Chem. 2010;50(2):106-13. https://doi.org/10.1134/S096554411 0020040 .
Furimsky E. Metal carbides and nitrides as potential catalysts for hydroprocessing. Appl Catal A. 2003;240(1-2):1-28. https://doi. org/10.1016/S0926-860X(02)00428-3.

Golovko AK, Kopytov MA, Sharonova OM, Kirik NP, Anshits AG. Cracking of heavy oils using catalytic additives based on coal fly ash ferrospheres. Catal Ind. 2015;7(4):293-300. https://doi. org/10.1134/S2070050415040078.

Holda P, Jose LP, Montoya de la Fuente JA, Marcos M. Effect of metal loading in $\mathrm{NiMo} / \mathrm{Al} 2 \mathrm{O} 3$ catalysts for maya vacuum residue hydrocracking. Energy Fuels. 2017;31(5):4843-50. https://doi. org/10.1021/acs.energyfuels.7b00104.

Kadiev HM, Khadzhiev SN, Kadieva MKh, Dow ES. Ex situ synthesis of sulfidized molybdenum-containing ultrafine hydroconversion catalysts. Nanoheterogeneous Catalysis. 2017;2(1):64-73. https ://doi.org/10.1134/S2414215817010038.

Ledoux MJ, Pram HuuC, Guille J, Dunlop H. Compared activities of platinum and high specific surface area $\mathrm{Mo}_{2} \mathrm{C}$ and WC catalysts for reforming reactions: I. Catalyst activation and stabilization: reaction of $\mathrm{n}$-hexane. J Catal. 1992;134(2):383-98. https://doi. org/10.1016/0021-9517(92)90329-G.

León AY, Guzman A, Laverde D, Chaudhari R, Subramaniam B, Bravo-Suárez JJ. Thermal cracking and catalytic hydrocracking of a colombian vacuum residue and its maltenes and asphaltenes fractions in toluene. Energy Fuels. 2017;3(14):3868-77. https:// doi.org/10.1021/acs.energyfuels.7b00078.

MacAdams LA, Buffone GP, Incarvito CD, Rheingold AL, Theopold $\mathrm{KH}$. A chromium catalyst for the polymerization of ethylene as a homogeneous model for the phillips catalyst. J Am Chem Soc. 2005;127(4):1082-3. https://doi.org/10.1021/ja043877x.

Meena MM, Edward F. Hydroprocessing catalysts containing noble metals: deactivation, regeneration, metals reclamation, environment and safety. Energy Fuels. 2017;31:5711-50. https://doi. org/10.1021/acs.energyfuels.7b00471.

Morozov MA, Akimov AS, Zhuravkov SP, Zolotukhina NYu, Sviridenko NN, Golovko AK, et al. Catalytic properties of tungsten carbide powders in the course of cracking of heavy hydrocarbon feedstocks. Bull Tomsk Polytechn Univ. 2017;328(8):16-24.

Nassar NN, Hassan A, Pereira-Almao P. Application of nanotechnology for fuel oil upgrading catalytic steam gasification-cracking of asphaltenes. Energy Fuels. 2011;25(4):1566-70. https://doi. org/10.1021/ef2001772.

Okunev AG, Parkhomchuk EV, Lysikov AI, Parunin PD, Semeikina VS, Parmon VN. Catalytic hydroprocessing of heavy oil feedstocks. Russ Chem Rev. 2015;84(9):981-99. https://doi. org/10.1070/RCR4486.

Rodella CB, Barrett DH, Moya SF, Figueroa SJA, Pimenta MTB, Antonio Aprigio S. Curvelobc and Victor Teixeira da Silva Physical and chemical studies of tungsten carbide catalysts: effects of Ni promotion and sulphonated carbon. R Soc Chem. 2015;30(5):23874-85. https://doi.org/10.1039/C5RA03252K.

Semin GL, Dubrovskii AR, Snytnikov PV, Kuznetsov SA, Sobyanin VA. Using catalysts based on molybdenum and tungsten carbides in the water-gas shift reaction. Catal Ind. 2012;4(1):59-66. https ://doi.org/10.1134/S2070050412010102.

STO 1246-2011. Method for determination of SARA "Mass fraction of resin-asphaltene substances in oils, oil fractions, natural bitumen, coal, organic matter of rocks, products of thermolysis of kerogen and coal. Gravimetric method of measurement". Institute of Petroleum Chemistry SB RAS. Published on May 12th, 2011.

Sviridenko NN, Krivtsov EB, Golovko AK. Effect of ferrospheres as additives on the composition of cracking liquid products of Mordovo-Karmal Native Bitumen. Chem Technol Fuels Oils. 2016a;52(3):285-92. https://doi.org/10.1007/s10553-016-0705-2.

Sviridenko NN, Krivtsov EB, Golovko AK. Cracking of Natural Bitumen in the presence of $\mathrm{Mo}$ and $\mathrm{CuO}$ nanosized powders. Pet Coal. 2016b;58(7):732-5. 
Sviridenko NN, Krivtsov EB, Golovko AK. Cracking of vacuum residue in the presence of nanosized powder of tungsten carbide and nichrome. Chem Sustain Dev. 2018;4:427-34. https://doi. org/10.15372/KhUR20180410.

Wang J, Li C, Zhang L, Deng W, Que G. Phase separation and colloidal stability change of karamay residue oil during thermal reaction. Energy Fuels. 2009;23(6):3002-7. https://doi.org/10.1021/ef801 $149 \mathrm{q}$.

Yakubov MR, Borisov DN, Maganov NU, Rempel RD, Ainullov TS, Sakhabutdinov RZ, et al. Novel approaches and prospects for upgrading of extra-viscous oil via thermolysis under various conditions. Oil Ind. 2016a;5:74-6.
Yakubov MR, Milordov DV, Yakubova SG, Borisov DN, Gryaznov PI, Mironov NA, et al. Features of the composition of vanadyl porphyrins in the crude extract of asphaltenes of heavy oil with high vanadium content. Pet Sci Technol. 2016b;34(2):177-83. https:// doi.org/10.1080/10916466.2015.1122627.

Yakubov MR, Milordov DV, Yakubova SG, Borisov DN, Ivanov VT, Sinyashin KO. Concentrations of vanadium and nickel and their ratio in heavy oil asphaltenes. Pet Chem. 2016c;56(1):16-20. https ://doi.org/10.1134/S0965544116010072. 